\title{
The Problem of Scale \\ in \\ Human/Environment Relationships
}

\section{Oran R. Young}

Please note: This is a rough draft prepared for the conference on "Institutional Dimensions of Cooperation and Discord: Local and Global Cooperation" and circulated for reactions from colleagues only.

Long familiar to natural scientists, the problem of scale does not figure prominently in the discourse of the social sciences. Yet, in principle, matters of scale are just as pertinent to the growth of knowledge about social systems as they are to the development of understanding of physical and biological systems. In this essay, I endeavor to bring the problem of scale to the attention of students of social phenomena. My strategy for doing so is to consider in some depth similarities and differences between analyses of micro-level and macro-level institutions governing human/environment relationships. In the process, I hope to initiate a larger dialogue regarding the problem of scale among social scientists concerned with a wide range of subjects.

The problem of scale revolves around the transferability of propositions from one level to another in the dimensions of space and time. Scaling up, then, refers to the application of propositions about micro-scale systems to meso-scale and macro-scale 
phenomena. Scaling down involves the opposite tack, the application of propositions about macro-scale systems to meso-scale or microscale phenomena. A few examples from the natural sciences will lend substance to these conceptual points. Those working on the development of general circulation models (GCMs) as a means of understanding climate change are regularly asked about the prospects for scaling down from the global to the regional level. That is, many of those concerned about climate change want to know whether propositions pertaining to the global climate system can shed light on the prospects for climate variability at the regional or even the subregional level. Conversely, ecologists working on individual, self-contained ecosystems are often asked whether their knowledge of ecosystem dynamics applies at the landscape level or even at the planetary level. Much of the thinking underlying the Gaia hypothesis, for instance, is premised on the idea that the Earth itself is an ecosystem that ought to behave in accordance with principles derived from the study of smaller scale ecosystems.

Similar examples are easy to come by with regard to the dimension of time. There is great interest today, for example, in the feasibility of scaling up from propositions about interannual climate variability, caused by such forces as the El Nino phenomenon or volcanic eruptions, to propositions about variability at the decadal level, as in the case of cycles associated with sunspot activity. At the same time, those who work on macro-scale phenomena, like glacial cycles or the controversial Malenkovich cycle, are concerned with the prospects for scaling down or, in other words, investigating the 
applicability of their findings about long cycles to interannual or decadal cycles. Although space and time are distinct dimensions, the problem of scale is the same in both instances. Ultimately, it concerns the extent to which the underlying mechanisms at work at the various levels are sufficiently similar so that it is possible to make use of ideas and insights developed at one level in our efforts to understand phenomena occurring at other levels.

\section{Human/Environment Relationships}

Turn now to the substantive focus of this essay. The last decade has witnessed a striking growth of interest in the study of human/environment relationships at two distinct scales. One of the resultant bodies of literature, centered on the idea of governing the commons (Ostrom 1990), focuses on common property resources (or CPRs) and explores the role of social institutions as determinants of collective outcomes in smallscale, stateless societies. Inspired by the observation that the so-called "tragedy of the commons" (Hardin 1968) frequently fails to occur in practice, analyses of CPRs have done much to illuminate the conditions under which self-interested actors are able to use natural resources sustainably in the absence of an overarching public authority capable of making and enforcing rules governing the use of the resources at stake (McCay and Acheson eds. 1987, Bromley ed. 1992).

The other body of literature, closely tied to the "new institutionalism" in international relations, seeks to delineate the 
conditions under which cooperation can emerge and become institutionalized in international society (Hughes 1992, Milner 1992). Energized by the realization that many international interactions do not conform to the non-cooperative logic of the prisoner's dilemma (Axelrod 1984), studies of resource regimes at the international level have gone some way toward pinpointing the conditions that account for the variance in outcomes flowing from efforts to devise governance systems dealing with human/environment relationships (Young 1989).

The problem of scale posed by the emergence of these two bodies of literature is straightforward. Can we scale up from the study of CPRs in smallscale societies to the level of international society? To what extent, for example, do propositions concerning the conditions governing success in avoiding the "tragedy of the commons" in smallscale systems hold at the international level? Conversely, can we scale down from the level of international society to smallscale systems? Is the process of establishing social practices to guide the use of CPRs in smallscale, stateless societies, for instance, governed by the same forces as the formation of international resource regimes? In the discussion to follow, I explore this subject in some detail. To make the analysis easy to follow, I organize the argument around seven themes: (1) analytic puzzles, (2) social settings, (3) the nature of institutions, (4) the formation of institutions, (5) the consequences of institutions, (6) the performance of institutions, and (7) design principles. 


\section{Analytic Puzzles}

Each of the literatures under consideration rests squarely on the premises that interactive decisionmaking is the norm in human affairs and that collective-action problems are endemic in a world of interactive decisionmaking (Hardin 1982). They both assume as well that a sizable fraction of the variance in human/environment relationships can be explained in terms of the operation of social institutions (Elster 1989, Furubton and Richter eds., 1991). These are major points of tangency. But despite their obvious similarities, studies of CPRs and of resource regimes exhibit pronounced differences. This is attributable, in the first instance, to the way in which each stream of analysis frames its central analytic puzzle.

At the heart of the literature on CPRs lies the concept of common property or, in other words, property in which possessory and disposition rights are held jointly by the members of a social group while use rights are exercised individually by the members of the group (Feeny, Birkes. McCay, and Acheson 1990). All such arrangements harbor the potential for triggering the "tragedy of the commons," a vicious circle arising from the unwillingness or inability of individual users to internalize the social costs of their own actions (Gordon 1954, Scott 1955). Conventional wisdom has long held that the way to avoid these problems in human/environment relationships is to dispense with common property altogether and to replace such arrangements with private property or, in some accounts, with public property (Hardin and Baden eds. 1977). In a 
sense, the study of CPRs can be seen as an effort to refute this conventional wisdom and to put in its place a set of propositions recognizing the important role that common property arrangements play in many smallscale societies. The key move in this analytic project is the observation that structures of common property are regularly coupled with more or less extensive codes of conduct or social practices that guide the behavior of users of CPRs. Once made, this move leads to a search for conditions governing the establishment of such codes of conduct as well as to an effort to compare and contrast the performance of the resultant restricted common property arrangements and of private or public property in terms of criteria like sustainability, efficiency, and equity (McKean $1992)$.

The literature on resource regimes in international society, by contrast, starts from a concern with the nature of collective-action problems more generally. Rather than focusing on the behavior of users of CPRs, it seeks to classify collective-action problems into analytically distinct categories, like coordination, assurance, battle of the sexes, chicken, and prisoner's dilemma, and to ask about ways to avoid suboptimal outcomes in situations exhibiting these characteristics (Snidal 1985, Snidal 1991, Rittberger ed. 1990). One response, now receiving concentrated attention on the part of students of international relations, is that the answer lies in the creation of appropriate institutions or, in other words socially defined systems of roles, rules, and relationships (Krasner ed. 1983). The result is a generic analysis of the factors at play in the formation 
of regimes or governance systems and of the conditions that determine the effectiveness of these institutional arrangements once they are in place. In bringing this analysis to bear on human/environment relationships, those interested in resource regimes have sought to differentiate a number of types of problems, including international commons, shared natural resources, and transboundary externalities, and to evaluate the institutional mechanisms needed to solve each class of problems (Haas, Keohane, and Levy eds. 1983, Young 1994).

Whereas the literature on smallscale systems starts with the specific problem of avoiding the "tragedy of the commons" in the use of CPRs and seeks to extend the analysis step-by-step to other (related) problems, therefore, the literature on international society begins with the more abstract problem of understanding the bases for sustained cooperation in a stateless society and endeavors to apply its conclusions to a variety of substantive matters, including the collective-action problem associated with common property. The virtue of the first approach is its focus on a well-defined puzzle that is widely understood to be important. Its weakness is that it sometimes proves difficult or awkward to frame more complex concerns (for example, issues relating to the mixed systems of property rights characteristic of commonfield agriculture or subsistence hunting and gathering) within this conceptual framework. The picture emerging from the study of international resource regimes is just the opposite. This literature offers a more comprehensive taxonomy of issues associated with 
human/environment relationships. But it lacks the sharp focus afforded by the intense concern for escaping the "tragedy of the commons" that provides the motivating puzzle of the literature on CPRs.

\section{Social Settings}

Underlying this difference in analytic strategies and partially concealed by the framing of the central puzzles energizing the two lines of enquiry are some important differences in the nature of the social settings under consideration. Whereas structures of property rights, in the sense of institutional arrangements organized around the entitlements of ownership, loom large in smallscale societies, they have no direct or immediate counterparts in international society. The members of international society do not own the territories they occupy in the ordinary sense of the term. Rather, they possess jurisdiction over specified areas and exercise authority over the use of resources lying within their jurisdictional boundaries (Schachter 1991). To be more specific, res communis as the concept is used in modern international law differs significantly from common property in domestic or traditional law. Res communis, including the high seas, the stratospheric ozone layer, the global climate system, the geostationary orbit, and outer space, features shared jurisdiction rather than shared property rights. Use rights regarding such resources typically run with individuals or organizations (such as fishers, shipping companies, or airlines) subject to codes of conduct 
adopted and implemented by the states possessing jurisdiction over the resources in question.

This leads directly to the observation that resource regimes in international society encompass an added dimension that has no real counterpart in smallscale societies. Although the members of international regimes are ordinarily states, the actors whose behavior is at stake are often private individuals or corporations who are nationals of member states or who are subject to the jurisdiction of one or more of the member states for otfher reasons. In effect, member states assume responsibility for implementing the provisions of international regimes within their own jurisdictions Jacobson and Weiss 1991). This requires a second level of rule making coupled with an effort on the part of public authorities to elicit compliance from the users of the resources in question; often it raises questions about the capacity of these agencies to deal effectively with obligations relating to implementation and compliance they have assumed under the terms of international agreements. It is hardly surprising, under the circumstances, that rules making perfectly good sense in connection with the activities of individual users of CPRs do not always prove effective in the twostage process of institution building characteristic of international society.

To this we must add the fact that states as members of international regimes are collective entities whose interactive behavior is the product of domestic processes that are often both 
complex and unpredictable. This is the central insight of those who speak of the logic of two-level games (Putnam 1988) and who advocate bringing the second image back in (Zurn 1993) to understand both the processes of regime formation and the effectiveness of institutional arrangements once they are in place. Of course, it is possible to argue that the individuals who constitute the principal subjects of common property arrangements in smallscale societies sometimes experience inner conflict regarding their participation in such arrangements. In cases where clans, siidas, moieties, and so forth are the real decisionmaking units, moreover, the distinction is even less sharp. Still, it is hard to avoid the conclusion that the complexities arising from the fact that states are collective entities add a whole new dimension to the study of the collection-action problems associated with interactive decisionmaking among goal-directed actors.

Among other things, this raises important questions about the role of community in solving collective-action problems. If by community we mean a social group possessing shared beliefs, a stable membership, the expectation of continuing interaction, and a pattern of relations that are direct and multiplex (Singleton and Taylor 1992), it is apparent that there are sharp differences between international society and most smallscale societies on this dimension. Of course, it is easy to allow sentimentality to lead us to exaggerate the role of community in smallscale societies. Many of these societies have been characterized by deep social fissures, not to mention rapid change at a variety of levels. Similarly, there is a case to be made 
that shared beliefs do exert real influence on the behavior of policymakers at the international level, and through them on the behavior of states themselves. Even so, we should be wary about casual assertions regarding the existence of an international community and, as a result, about the transferability of arguments pertaining to the role of community in solving collective-action problems from the level of smallscale societies (Ostrom 1992) to the level of international society.

\section{The Nature of Institutions}

Both streams of analysis reflect the influence of the "new institutionalism," an intellectual movement now making its mark throughout the social sciences (Eggertsson 1990, Furubotn and Richter eds. 1991, Powell and Dimaggio eds. 1991). They are unified in their commitment to the proposition that social institutions, in contrast to material conditions and ideas (Cox 1986), account for a large proportion of the variance in the outcomes flowing from interactive behavior. They agree, as well, on a conception of institutions as rules of the game or codes of conduct that define social practices, assign roles to the participants in those practices, and guide interactions among the occupants of these roles. Among other things, this conception accents the distinction between institutions, on the one hand, and organizations, treated as material entities possessing offices, personnel, and budgets, on the other (Young 1989). 
These are strong bonds. Even so, there are notable differences between the two lines of enquiry regarding the domain of institutions or, in other words, the boundaries of the class of phenomena included under the rubric of institutions. Focusing on institutions as spontaneous or self-generating arrangements, the literature on CPRs includes informal or de facto codes of conduct passed from generation to generation through a process of socialization. This implies, among other things, that individuals have little choice regarding participation in the social practices they inherit. By contrast, students of resource regimes have moved toward a conception of institutions centering on roles and rules articulated explicitly in the provisions of treaties, conventions, or other (not necessarily legally binding) international agreements (Regimes Summit 1991). Given the prevailing understanding of sovereignty, individual members of international society are regarded as free from any obligation to comply with the terms of regimes unless and until they make an explicit decision to participate in them.

It is easy to overdo this distinction. A growing body of case studies suggests that participants in CPRs often articulate the rules of the game in an explicit manner, whether or not they choose to formalize them in constitutive documents. Regardless of the force of social pressure, moreover, individual users of CPRs are not wholly programmed by processes of socialization. It is now apparent, for instance, that many - perhaps most - ecosystems change too rapidly and unpredictably as a consequence of natural forces to allow static 
institutional arrangements to succeed in producing sustainable human/environment relationships. Nor are international resource regimes confined to the formal provisions laid out in constitutive documents. In some cases, the provisions of treaties and conventions (for example, the 1982 Convention on the Law of the Sea) simply ratify arrangements that have emerged informally over a period of time. What is more, international practices regularly evolve over time to meet changing circumstances, whether or not they are amended or altered in any formal sense. Equally important is the fact that individual states commonly experience social pressure to participate in resource regimes, regardless of their sovereign rights. The result, more often than not, is a complex combination of behavior that actually conforms to the requirements of regimes coupled with declaratory policies asserting sovereign rights.

Nonetheless, the two lines of enquiry pose contrasting dilemmas for those engaged in the analysis of social institutions and concerned with the transferability of propositions between microscale and macro-scale phenomena. Stressing informal arrangements, the literature on CPRs faces problems in pinning down the rules of the game precisely and separating institutions clearly from the social settings in which they operate. There is the danger here not only of being unable to generalize about institutional matters with confidence but also of falling prey to the temptation to save hypotheses by altering the content of the universe of cases under consideration. Focusing on codes of conduct articulated explicitly in constitutive documents, by contrast, the literature on international 
resource regimes avoids these problems of operationalization. Instead, it runs the risk of excessive formalism in the sense of assuming that rules in practice conform to the rules articulated in constitutive documents; it tends as well to ignore institutional arrangements that are important determinants of behavior though they are informal in nature. Each of these dilemmas is significant in its own right. But in terms of the present discussion of scale, their significance is that they raise serious questions concerning the comparability of the universe of cases considered by the two streams of analysis.

\section{The Formation of Institutions}

How do institutions (re)form in specific social settings? To what extent are lessons regarding institutional dynamics transferable from smallscale, stateless societies to international society and vice versa? Given what I have said already, it will come as no surprise that the two literatures start from divergent vantage points in seeking answers to these questions. Regarding institutions as self-generating arrangements (Hayek 1973), the mainstream literature on CPRs seeks to explain their development in terms of the diffusion of ideas and the convergence of expectations in the absence of formal negotiation. The evolution of rules governing exchange relationships - including the barter arrangements characteristic of subsistence systems as well as natural markets - constitutes a prominent case in point. Students of international regimes, on the other hand, have concentrated on explicit negotiations leading to agreement on the 
terms of treaties or conventions (Young and Osherenko eds. 1993). The central debate in this intellectual community concerns the relative importance of structural power in contrast to other driving forces as determinants of the content of the agreements reached (Keohane 1984).

One approach to reconciling this analytic disparity involves the introduction of a distinction between the negotiation stage and the prenegotiation stage of institutional development (Stein ed. 1989). Prenegotiation encompasses those processes through which issues emerge on the public agenda, are framed or defined for consideration on the part of those concerned with collective action, and rise to a sufficiently prominent place on the agenda to merit concentrated attention. The negotiation stage, on this account, refers to efforts to arrive at mutually agreeable arrangements once a problem is welldefined and ripe for action. The point of introducing this distinction is to suggest both that the formation of resource regimes in international society includes a prenegotiation stage that is heavily influenced by the diffusion of ideas and the convergence of expectations and that the formation of systems of property rights in smallscale societies encompasses a stage that can be properly construed as negotiation even when the results are not formalized in constitutive documents. In effect, both stages occur at the microlevel as well as the macro-level, though the prominence of each may vary from case to case and analysts working at the different levels have chosen to highlight one or the other stage in their thinking about the development of social practices. 
Additionally, it now seems apparent that equifinality figures prominently in processes of institutional development at all levels of social organization (Young and Osherenko eds. 1993). What this means is that we can identify several distinct tracks or paths leading to success in the (re)formation of institutional arrangements in smallscale societies and in international society alike. Just as the participation of a dominant actor may be critical in the establishment of international regimes, the leadership of a key individual may be an essential feature of institution building in smallscale settings. Similar observations are in order about paths characterized by explicit or overt negotiation among a group of actors more evenly matched in terms of their bargaining strength and by tacit interactions driven by the convergence of expectations around salient solutions in contrast to the convergence of offers through some reciprocal concession mechanism. All these processes producing what may be described as imposed arrangements, negotiated arrangements, and self-generating arrangements (Young 1989) - are clearly in evidence in the case studies produced by students of international regimes and students of arrangements arising to deal with CPRs in smallscale societies. There may, of course, by differences from one society to another in the prominence of these paths. But the point I want to emphasize here is that some of the apparent disparity between the two streams of analysis regarding institutional development is a matter of emphasis on the part of analysts rather than actual differences in the phenomena under consideration. 


\section{The Consequences of Institutions}

Do institutions matter (Haas 1989)? Put another way, what proportion of the variance in collective outcomes in the realm of human/environment relationships can be explained in terms of the operation of systems of property rights or resource regimes (Young 1992)? The initial responses of the two streams of analysis to these questions are strikingly different. The mainstream literature on CPRs - like the mainstream literature on most micro-scale and meso-scale social systems - simply takes it for granted that institutions are major determinants of collective outcomes and concentrates on assessing these consequences in terms of a variety of criteria of evaluation. Students of international regimes, by contrast, must confront the deepseated skepticism of most realists and many neorealists who see institutions largely as epiphenomena at the international level. The argument here is that institutional arrangements are fundamentally reflections of the underlying configuration of power in international society which can be expected to change whenever the underlying configuration of power shifts (Strange 1983).

Whatever the merits of these disparate perspectives in their own terms, the clash between them suggests the importance of addressing the issue of demonstrating the existence and strength of causal connections between institutions and collective outcomes at all levels of social organization. The mere fact that changes in collective 
outcomes follow the establishment of new institutions or the restructuring of existing institutions is not sufficient to prove a causal link; the danger of spurious correlation is far too great for that. What is more, the usual statistical procedures for weeding out spurious correlations cannot offer much help in assessing the role of institutions at either the micro-level or the macro-level. Not only is it hard to operationalize the key variables for purposes of quantitative analysis but we are also seldom in a position to draw representative samples from some larger universe of cases.

Two lines of attack seem helpful in this connection (Levy and Young 1993). In the first instance, it is possible to probe the strength of inferred links between social practices and collective outcomes through a combination of natural experiments and thought experiments. It makes sense, for example, to look for situations that resemble each other closely except in the area of institutions and to ask about differences in the collective outcomes that ensue. There is much to be said, as well, for making a sustained effort to account for apparent links between institutions and outcomes in terms of rival hypotheses and to use the method of counterfactuals to ask what would have occurred in the absence of the relevant institutions (Fearon 1991, Biersteker 1993). In the final analysis, however, it seems essential in addressing this problem to work toward exposing the behavioral mechanisms through which institutions operate to affect behavior (Levy, Osherenko, and Young 1991). Because social scientists do not agree on the adequacy of a single model of behavior - especially where collective entities are concerned - this endeavor 
inevitably requires the specification of a set of behavioral models together with an effort to show step-by-step the causal chains leading from the existence of institutions to the interactive behavior of the relevant set of actors (Levy 1993). This is not an easy task; it is unlikely to produce a litmus test to be used in demonstrating the effectiveness of institutions. But in the long run, the construction of behavioral models will surely produce sizable rewards for those who currently take it for granted that institutions matter as well as for those who now face extreme skepticism from colleagues who believe that material conditions in general and structural power in particular determine the content of collective outcomes, regardless of the character of prevailing institutional arrangements.

\section{The Performance of Institutions}

Among those who are satisfied that institutions do account for a sizable proportion of the variance in collective outcomes, it is natural to move on to a study of the performance of social practices. In the first instance, this is a matter of problem solving or, in other words, the capacity of institutional arrangements to meet the challenges that motivate their establishment. Here, too, the initial biases of those who think about smallscale societies and those who focus on international society diverge quite sharply. Among students of CPRs, there is a distinct optimism regarding the capacity of institutions to circumvent the "tragedy of the commons," producing sustainable human/environment relationships in the process Most students of international affairs, by contrast, are inclined to see 
institutions as weak instruments that face an uphill battle in solving collective-action problems, except in those all too uncommon cases of assurance or coordination where no major conflicts of interest are involved.

What should we make of this disparity? On their own terms, these biases are not easy to justify. It is easy enough to find failures as well as successes in the efforts of the members of smallscale societies to solve collective-action problems. Equally important, there are striking differences among international resource regimes in their performance as problem-solving devices. This suggests that those who are now endeavoring to pin down conditions governing the success of institutional arrangements - whatever level they operate on - are on the right track (McKean 1992). It also affords striking opportunities for mutually beneficial interactions between those focusing on micro-scale systems and those who work at the macro-scale. Recent studies dealing with matters like the importance of institutional flexibility as a means of dealing with changing ecosystems and of the role of transparency as a determinant of compliance with regulative rules (Chayes and Chayes 1993) offer strong evidence of the value of efforts to scale up and down in this area of enquiry.

Beyond this, any consideration of the performance of social institutions must come to terms with issues pertaining to efficiency and equity as well as with the issue of problem solving per se. A frequent criticism of common property arrangements, for example, is 
that they harbor strong biases toward the status quo because they do not provide adequate incentives for innovation or growth, whatever their merits in avoiding the "tragedy of the commons" (Field 1990) International regimes, by contrast, are sometimes criticized as devices created by the privileged members of international society for the purpose of perpetuating the current highly asymmetrical distribution of wealth between the rich and the poor. My point in introducing these examples is not to debate their validity at either the micro-scale or the macro-scale. Rather, I want to suggest, to begin with, that once the causal role of institutions is acknowledged, it is natural to begin asking pointed questions about their performance in terms of criteria like efficiency and equity and, beyond this, that this is another area where students of smallscale societies and students of international society have much to contribute to each other's thinking. In effect, it is time to set aside the preoccupation with the "tragedy of the commons" at the microscale and the battle over the consequentiality of institutions at the macro-scale and move toward a more sophisticated analysis of the performance of institutions fueled by an ongoing dialogue between those concerned with the two scales.

\section{Design Principles}

It is natural for those who study institutional arrangements governing human/environment relationships to take a strong interest in design principles (Ostrom 1990). Partly, this is a matter of joining theory and practice in the interests of deepening our 
knowledge of social institutions. There are obvious advantages from an analytic point of view in linking basic and applied research in such a way as to test and refine theoretical arguments in the light of actual experience and to organize thinking about current problems in terms of theoretically significant categories. In considerable part, however, it is the prospect of extracting design principles from the study of institutions that makes research in this field relevant to the concerns of policymakers and that provides the rationale for continuing to provide the resources needed to underwrite ongoing research in this promising field enquiry.

This said, it is worth noting that students of smallscale systems and international society alike face serious questions concerning the feasibility of formulating design principles that will prove helpful to those responsible for working out the terms of institutions in specific cases. For their part, those interested in CPRs have emphasized the spontaneous or self-generating nature of common property systems, a position likely to appeal to conservatives who maintain that deliberate intervention in the processes through which institutions develop is either unnecessary or infeasible or both (Ellickson 1991). Additionally, this stream of analysis does better in dealing with selfcontained traditional societies than with contemporary situations featuring complex mixes of traditional common property arrangements and recent interventions stemming from the policy initiatives of modern states (Jodha 1993). There is a real danger, under the circumstances, that the design principles emanating from 
this stream of analysis will be most relevant to a universe of cases encompassing a declining set of members.

Turning to international society, the questions concern the causal role of institutions and the extent to which it is feasible to generalize from one case to another. To the extent that the realists are right in treating international institutions as epiphenomena, any effort to formulate design principles will be fundamentally an exercise in futility. It is this observation that has led some to cite the fact that policymakers regularly work hard to devise international institutions together with the premise that it is improbable that they are all deluded as evidence that institutions really do matter in international society (Chayes and Chayes 1993). It is undeniable, as well, that this stream of analysis includes a good deal of facile thinking regarding the generalizability of findings about resource regimes from one case to another. Many recent efforts to apply ideas drawn from the case of ozone depletion to other current concerns, like climate change and the loss of biological diversity, illustrate this danger (Sebenius 1991).

What is more, the process of forming institutions is itself a matter of collective action at all levels of social organization (Young 1982). Put another way, the terms of social practices are products of interactions among self-interested parties, whether the process is one featuring the convergence of expectations as envisioned by those who focus on spontaneous arrangements or explicit bargaining as suggested by those who think in terms of negotiated arrangements. 
In either case, it follows that institutions are not created by unitary actors able and willing to design principles in a rational or goaldirected manner. Certainly, this does not make the search for design principles irrelevant. But it does politicize and, therefore, greatly complicate the view of institutional design implicit in many accounts of the role of knowledge in the creation of social institutions (P. Haas ed. 1992).

None of this is likely to deter analysts from seeking to extract design principles from their studies of social institutions suitable for use by policymakers struggling to deal with specific cases. What is to be gained, then, from revisiting the problem of scale with a concern for the formulation of design principles? The answer, I now believe, depends on how problems to be solved through the creation of institutions are framed. To the extent that students of international regimes focus on the implementation of the provisions of treaties within the domestic legal and political systems of the member states, for example, there is little prospect that propositions derived from the study of smallscale systems will prove helpful. Yet it seems distinctly interesting to compare the findings of the two streams of analysis regarding the role of transparency, monitoring, and implementation review procedures as determinants of compliance on the part of those subject to the rules of social institutions. Similarly, many of the arguments about the role of culture articulated by students of smallscale societies (McCay 1993) seem to me to have little applicability to the world of international regimes. But there is mounting evidence to suggest that social learning, in contrast to the 
deployment of bargaining strength, plays an important role in the evolution of institutional arrangements at both the micro-scale and the macro-scale (E. Haas 1990). The conclusion I draw from these observations is that the solution to the problem of scale is by no means clearcut in connection with the streams of analysis under consideration. Transfer ability is hardly an all-or-nothing affair; the feasibility of applying propositions across levels will often be affected by the way in which the issues to be addressed are framed .

\section{Conclusion}

What can we conclude from this brief account of scaling up and scaling down in connection with social institutions governing human/environment relationships that will be of interest to social scientists contemplating the problem of scale more generally. First and foremost is a warning about the dangers of simplistic reasoning. Macro-scale systems are not simply smallscale systems writ large. Nor are micro-scale systems mere microcosms of largescale systems. It follows that we cannot simply assume that the mechanisms at work at the two levels are the same and that any effort to transfer propositions from one level to another or, in other words, to scale up and scale down should be treated with a healthy sense of skepticism. This may be unwelcome news for social scientists who adhere to doctrines like methodological individualism. But it seems difficult to justify any other conclusion on the basis of this case study. 
This said, however, the case I have discussed does suggest that there is great scope for cross-fertilization among studies of social phenomena conducted at different scales. The literatures under consideration here have in common a focus on interactive decisionmaking, a concern with collective-action problems, and an interest in the role of institutions as devices for solving or avoiding these problems. These are major points of tangency. Under the circumstances, there is much to be said for thinking carefully about both common themes that unite the two literatures and analytic disparities that divide them. The observation that transparency is an important determinant of compliant behavior at both scales, for example, is a striking finding. By contrast, the realization that two streams of analysis that share so much can frame their central analytic puzzles so differently is a sobering thought. But in either case, we all stand to benefit from an effort to sort out what is transferable across scales and what is peculiar to micro-scale or macro-scale systems in the realm of human/environment relations.

\section{Literature Cited}

[to come]

\section{Please send comments to:}

Oran R. Young Institute on International Environmental Governance 6193 Murdough Center

Dartmouth College

Hanover, New Hampshire 03755

oran.r.young@dartmouth.edu 